\title{
O paradoxo do camaleão: identidade $e$ modernidade líquida segundo a análise de Zygmunt Bauman
}

\author{
Jéssica Soares Silva
}

Lucas Ariel Azeredo Sales Gama e Silva²

\section{RESUMO}

O objetivo precípuo deste presente artigo é examinar o processo de construção e manutenção da identidade social do indivíduo diante dos desafios fragmentadores do mundo líquido pós-moderno presente na análise e descrição sociológica a obra do polonês Zygmunt Bauman. O mecanismo de construção identitária é estudado a partir de profunda pesquisa bibliográfica sobre os escritos do autor e de outros influentes sociólogos que contribuíram para a estudo da problemática. A compreensão central está pautada na identidade como um processo ambivalente que oferece liberdades, amplitudes de ação e pluralidades e ao mesmo tempo produz uma imensa sensação de angústia no indivíduo líquido moderno. Para tal intento, cria-se a alegoria do camaleão social como um ser que reconfigura seus atributos e identidades à medida em que o contexto assim o exige.Temas como sociedade de consumo, papéis sociais e globalização perpassam a proposição fundamental.

Palavras-chave: Identidade; Modernidade líquida; Ambivalência.

\footnotetext{
${ }^{1}$ Bacharel em Ciências Sociais pela Universidade Estadual do Ceará, Mestre em Sociologia pela Universidade Federal do Ceará. É socióloga na Prefeitura Municipal de Eusébio-CE. E-mail: jessicasoares@gmail.com.

2 Bacharel em Sociologia pela Universidade Estadual do Ceará. Possui especialização em Metodologia de Enfrentamento a Violência Contra a Criança pelo Centro Universitário 7 de Setembro. É sociólogo na Prefeitura Municipal de Eusébio-CE E-mail: lucasazeredo@live.com.
} 


\begin{abstract}
$\mathrm{A}_{\mathrm{i}}$ intenção do presente artigo é desenvolver uma discussão, sob o viés do estudo das obras de Zygmunt Bauman, das formações e manutenções dos processos de formação identitárias dos indivíduos na condição da vida líquida pós-moderna atual.

As escolhas metodológicas para a construção desse artigo se formaram por meio de profunda pesquisa bibliográfica nas obras de Bauman, por considerarmos a relevância do mesmo para melhor percepção das nuances e problemáticas oriundas da pós-modernidade que que vivemos enquanto indivíduos e sociedade. A escolha das obras de Bauman se deram como mote a dar embasamento à questão proposta de discussão do camaleão social, para isso "Modernidade Líquida", "Identidade", "Capitalismo parasitário" e "Cultura no mundo líquido moderno" se mostraram mais apropriadas para o desenvolvimento do artigo, dentre a larga quantidade de obras publicadas do autor escolhido.

O artigo é composto por um introdução, três partes/capítulos (Dialogando com Bauman, A questão da identidade; O paradoxo do camaleão) e uma conclusão. A primeira parte do texto se propõe a trazer um panorama articulado dos conceitos de Bauman que serão discutidos no artigo. A segunda parte tem o objetivo de fazer uma breve interlocução sobre a questão identitária proposta em confluência com os conceitos de Bauman, enquanto que a terceira parte, concentra-se em desenvolver a proposta titular do artigo.
\end{abstract}

\title{
Dialogando com Bauman
}

Os escritos do sociólogo e pensador polonês Zygmunt Bauman ajudaram a construir um novo entendimento do fenômeno da pósmodernidade, segunda modernidade ou modernidade tardia. Sua análise sociológica é pautada na compreensão de que os tempos hodiernos são 
fluídos e estão em constante mudança e transformação, movimento este que impele o indivíduo a um comportamento novo perante o mundo social que o cerca. Para elucidar este entendimento, Bauman vale-se da metáfora do líquido - ou processo de liquefação - pelo qual passamos hoje, contruindo uma comparação com os estados físicos da matéria. Por certo, essa associação é um valioso elemento provocador de seu estudo que ajuda a desvendar os meandros do processo de volatização e fragmentação dos laços sociais nos dias atuais.

Todo esse processo se faz em contraposição com a intitulada modernidade sólida. Bauman a caracteriza pelo peso de suas normas e suas representações de poder que se organizavam nesta sociedade disciplinar e burocratizada, contextualizada nos escritos de Michel Foucault e Max Weber. A vigilância e o controle eram pilares desta solidez que constrangia o sujeito a obedecer padrões, rotinas e regulamentos. Temia-se de fato que o Estado invadisse a esfera particular do indivíduo e tomasse seu espaço de intimidade. A luta constante era guiada pelo desejo humano de mais liberdade e emancipação.

Conquanto esta modernidade sólida tenha reinado até a primeira metade do século XX absolutamente soberana, todos os prognósticos se mostraram terrivelmente equivocados quando Bauman relata o processo de liquefação pelo qual a sociedade passou no restante daquele século. As parcerias humanas foram assim precarizadas, as questões privadas passaram a invadir o discurso político e o capital dissociou-se do trabalho. Todas estas impressionantes transformações tiveram um relevante impacto sobre o sujeito e o processo de construção de sua identidade perante o mundo que agora se revela leve, instável, volátil e desafiador.

Por esta razão, a perspetiva de manter-se em permanente movimento é fundamento da modernidade líquida de Zygmunt Bauman. 
A comparação é interessante posto que o estado líquido é o meio termo entre o sólido e o gasoso. Ele preserva certos atributos do corpo sólido ao mesmo tempo em que demonstra caracteres da qualidade gasosa. É também maleável e pode remodelar-se com tremenda facilidade conforme a ocasião assim exija. Ademais, não tem forma definida e padronizá-lo é praticamente impossível, algo como pegar a água juntando as duas mãos:lentamente ela acabara escorregando por entre os dedos.

Nesta esteira, no novo mundo líquido moderno nada é feito para durar e a obsolescência está programada para o próximo minuto. Observe os bens de consumo, carros, celulares, máquinas de lavar roupas, televisores... como uma espécie de mágica eles param de funcionar corretamente e você descobre que o conserto é tão caro que vale mais a pena desfazer-se dos velhos aparelhos para comprar novos. Por isso, osujeito busca, como consumidor ávido por novidades de mercado, dentro desta lógica por uma instantânea satisfação no consumo desses produtos.

A tarefa de solidificar este fluido que Bauman nos conta é por demais penosa e fatigante para o indivíduo que tem que conviver com o constante temor de ver todo o seu esforço ser arruinado. Vincar raízes não parece um projeto atrativo e pode significar o empenho de seu futuro. Futuro este que permanece repleto de incertezas e por esta mesma razão um tanto mais tenebroso. As oportunidades podem aparecer e você não estará livre e apto para usufruí-las com liberdade por que se acorrentou as promessas passadas que hoje mais parecem fardos indesejados.

Com efeito, o comportamento social dos indivíduos assimilou este atributo da liquidez dinamizando as relações sociais ao ponto de transformá-las em meros encontros casuais e furtivos. A fragilidade dos laços entre indivíduos nessa modernidade líquida revelada por Bauman 
corrói a possibilidade de um projeto de vida duradouro e eficaz que possa nortear os rumos da existência do ser humano em sociedade. A título de exemplo, pense em um casamento longevo que dure várias décadas. Hoje este cenário parece cada vez mais ser uma exceção na sociedade e inclusive pode ser encarado com certo espanto por quem recebe a notícia dos anos passados dentro deste casamento.

Tudo isso produz uma imensa sensação de liberdade que induz o sujeito a manter-se leve e apartado de todo mecanismo de controle, forma ou padrão. Bauman relata que a modernidade pesada (sólida) fundou-se no entendimento de que o prospecto de vida para a felicidade do indivíduo estava na conquista de sua emancipação. O sonho mais tentador era romper com as amarras morais e políticas que limitavam o sujeito perante a coerção pesada do Estado. Era a época da racionalidade instrumental weberiana e da imagem do capitalismo sólido como uma jaula de ferro que, unida à engrenagem daburocracia, impingia severas restrições à construção do eu face ao mundo social circundante. $\mathrm{O}$ capital estava intimamente ligado ao trabalho e à expressão máxima do poder era a fábrica e seus pesados maquinários. Bauman toma como exemplo a figura de Henry Ford e sua linha de montagem em série nos primórdios da Administração Científica no início do século XX.

Destarte, em poucas décadas, Bauman afirma que toda essa realidade foi radicalmente transformada pelo fenômeno da liquefação. Os padrões foram se dissolvendo na hipervelocidade da modernidade líquida e seus novos imperativos. Assim, o indivíduo foi arrastado para o furação das transformações e toda a sociedade precisou ser remodelada. A questão identitária não escapou incólume dessa revolução. 


\section{A questão da identidade}

O processo de identificação do sujeito sociológico na pósmodernidade traduz um complexo e cada vez mais multifacetado laboratório de experiências descontínuas e fragmentadas. As práticas sociais flutuam agora sem um referencial antes dado pelo peso da tradição, gerando assim, uma sensação ambivalente de liberdade e desamparo. Stuart Hall - grande sociólogo jamaicano - utiliza o conceito de jogo de identidades para demonstrar que as particulares qualidades que individualizam o sujeito estão em constante interação e por vezes, até mesmo contradição (daí o evidente caráter relacional da identidade). Questões de gênero, etnia, classe social, nacionalidade, sexo, entre outras, são aspectos dessa vida moderna líquida multifacetada. Como exemplo, pense em um homem negro, gay, por volta de 30 anos, desempregado... todos esses elementos/traços compõem um poderoso sistema de representações que edifica múltiplas identidades neste sujeito social. Conforme o cenário onde este ator representar, essas diversas identidades podem trabalhar em conjunto ou em choque, inclusive, uma também pode sobrepujar a outra, consoante uma particular situação o demande. Em casa ele pode ser percebido primordialmente como negro pois sua família também se identifica com a sua negritude. Já no grupo de amigos ele pode ser reconhecido por sua orientação sexual. No trabalho pode ser avaliado por sua faixa etária e assim por diante.

Todos esses domínios identitários amoldam diferentes formas de viver a identidade dentro de um mesmo indivíduo. Stuart Hall examina este fenômeno e o intitula de política da identidade onde cada esfera simbólica tem seus próprios meios de vida. Ser negro, ser adulto, ser gay, ser pobre... todas essas são formas de vivenciar e experimentar o eu em interação com o mundo social. 
A incompletude imperativa que permeia a modernidade líquida atual é refletida também nas questões identitárias. De certo, a mudança constante e a incrível flexibilidade e maleabilidade com que os sujeitos se movimentam nas teias sociais geram um esforço ambivalente de construir sua identidade dentro de um arcabouço infinito de possibilidades de escolhas e tomadas de decisões. Por conseguinte, como nada é feito para durar, o indivíduo parece sentir a constante premência de reprogramar seus planos e visões de mundo na busca de uma adaptabilidade dos seus traços que lhe dê conforto para mudar de rumo assim que o cenário exigir esse movimento.

A compreensão desse processo e a própria reflexão acerca da identidade no mundo pós-moderno é um fator sintomático de que este tema se tornou deveras importante para permanecer de fora do rol de análise das Ciências Sociais. Consonante a esta análise, Bauman afirma que:

a ideia de ter uma identidade não vai ocorrer às pessoas enquanto o pertencimento continuar sendo o seu destino, uma condição sem alternativa. Só começarão a ter essa ideia na forma de uma tarefa a ser realizada, e realizada vezes e vezes sem conta, e não de uma só tacada (BAUMAN, 2005, p. 17-18).

O que o autor aqui explicita é o fato de a identidade hoje ser um fenômeno que necessita ser construído, posto que não mais é somentedado ao indivíduo no momento do seu nascimento pelo seio social da uma comunidade onde ele está inserido. A construção deidentidade que anteriormente precedia ao indivíduo, não apenas o faz, agora se comunga com a realização emum esforço de dar forma e solidez a volatividade do cotidiano líquido, meio este inundado de possibilidades e objetos sedutores. 
Nesse diapasão, prefere Stuart Hall observar a iteração do "eu” com o "mundo exterior", não por intermédio do conceito de identidade, mas sim de identificação. Assim como um processo relacional, algo que se forma e se deforma com o percurso do tempo e sob influência de inúmeros fatores políticos, históricos, econômicos, sociais, etc.

Para fazer um paralelo entre a relação Estado versus indivíduo, na modernidade sólida, a máquina estatal se sobrepunha ao sujeito e determinava basicamente qual era seu lugar no mundo. Não obstante tal realidade, hoje vive-se o império do homem sobre as instituições. Bauman percebe esse movimento como a formação da sociedade dos indivíduos onde a fragilidade dos laços sociais é algo tão manifesto que a solidão parece absolver o homem mesmo que este esteja rodeado por multidões.

Para exemplificar, as sociedades individualizadas na modernidade líquida têm nos smartphones e nas redes sociais seus mais nobres arquétipos. Dominados por esta realidade virtual, os sujeitos caminham indiferentes ao mundo real que os rodeia. A distração e a furtividade são evidentes e qualquer um pode esquivar-se de uma conversa indesejada ou de um encontro constrangedor simplesmente sacando o celular do bolso e acessandoà internet.

Assim, o esforço de empreender à construção do eu na modernidade fluída se faz à revelia de uma sociedade que pouco contribui para tal intento. A hipervelocidade com que a vida é conduzida não permite que a identidade tenha tempo para se solidificar e gerar um estável e estático propósito de vida. Tudo pode mudar, a qualquer momento, e em certo ponto é de desejo dos homens que se mude.

A comparação com a moda cai bem, pois pensar que as identidades podem ser "vestidas" e "descartadas" conforme o desejo do sujeito-consumidor, ajuda certamente a revelar a leveza e a fluidez dessa sociedade em constante mutação. Como toda boa moda, as roupas (e as 
identidades) devem mudar conforme breves espaços de tempo e de circunstâncias para manter os consumidores ávidos por novas tendências e captar assim, seus desejos e atenções por mais tempo.

Todavia, o impasse se estabelece no instante em que a questão identitária sofre com o movimento ambivalente (atrativo e ao mesmo tempo repulsivo) da sociedade líquida moderna. A dialética das identidades desenha um quadro instável de autointerpretação do indivíduo que pendula em sentir prazer na liberdade de construir seu “eu” e temor no fardo de ter de fazer isso sozinho. Pouco agora é dado previamente e muito é cobrado em relação as decisões individuais futuras. O sabor é doce no início, mas pode revelar-se amargo no final.

A leitura de Bauman acerca dessa ambivalência está no chamado “do it yourself" ou na "costumização" da vida. Dentro de uma abundante pluralidade de elementos, caminhos e visões de mundo, o indivíduo deve selecionar a que melhor o agrada no momento. Daí o sucesso dos serviços de streaming (Netflix, Spotify, Ifood, etc) atualmente. Você assiste o filme que quiser, escuta a música que quiser, come a comida que quiser. Conquanto, para isso, você precisa antes escolher num mar imenso de opções, aquela que melhor se encaixa com o seu desejo. A tarefa que inicialmente parece fácil e prazerosa pode tornar-se fatigante, pois toda escolha é uma renúncia e você nunca saberá se acabou por escolher o hambúrguer certo ou a música adequada. Em síntese, como responder a simples questões como: quem sou eu? O que eu desejo? Qual meu lugar no mundo? As conclusões podem ser abandonadas antes mesmo de gerar resultados gratificantes...

\section{O paradoxo do camaleão}

O indivíduo líquido moderno sofre com a sensação de não possuir mais âncoras para vincar seu barco-vida e enfim poder descansar 
ou - quem sabe - redefinir seus objetivos. Ele constata que se parar de velejar, por um só segundo que seja, vai contar com a força imprevisível do vento que sopra seu barco para qualquer lado. No fim, este movimento arriscado vai trazer para o sujeito uma sensação nada agradável de profunda desorientação e insegurança.

A ambivalência da questão identitária encontra-se exatamente neste ponto. Ao mesmo tempo em que a identidade tem seu escopo profícuo advindo do desejo de segurança e pertencimento, ela agora renega seu fator estabilizador e se fragiliza então em seu próprio fundamento de existência conceitual. Toda essa incongruência produz uma considerável carga de angústia e ansiedade nas pessoas que a experimentam, trazendo uma sensação de que a todo momento se faz necessário refletir se o caminho que tomaram diante das infinitas possibilidades a disposição eram de fato as mais proveitosas, fáceis, admiráveis ou relevantes.

Nessa esteira, como mecanismo que proteção, o indivíduo pósmoderno deve adotar a postura de um camaleão social.Como tal, deve estar sempre pronto para transmutar-se em algo totalmente novo conforme o contexto em que sua identidade e sua imagem social se apresentam. O deslocamento seria algo como a letra de uma famosa canção de Raul Seixas: ser uma metamorfose ambulante e não ter uma opinião formada sobre tudo!

A expressão em inglês gowiththeflow também ajuda a explicitar esse movimento de liquefação da sociedade e reafirma que se deve seguir o fluxo sem atravancar as velozes transformações. A postura cameleônica aqui serve inteiramente ao repto da construção de uma identidade fragilizada e cada vez mais fragmentada. Logo, hoje sou, amanhã posso não ser. Hoje quero, amanhã posso não mais querer.

Com efeito, a condição etérea da identidade do indivíduo moderno líquido sinaliza para a perfeita adequação com a alegoria do 
camaleão. A mudança de coloração da pele deste réptil é característica peculiar de seu comportamento social que por intermédio de um processo adaptativo chamado de camuflagem, encontra os meios de sua sobrevivência em seu habitat. Nesta conjectura apresentada, não há motivos para imbuir-se de uma identidade coesa e pesada que por certo limitaria o espectro de atuação do sujeito na selva de infinitas possibilidades sedutoras e instigantes. Nada de fincar raízes! Esqueça! A tática mais apropriada para admoestar a construção da identidade social é apresentar-se como um verdadeiro camaleão, pronto pra mudar de cor conforme as próximas circunstâncias assim o exijam.

Seguindo os escritos da teoria dramatúrgica de Goffman, o indivíduo representa um papel social como se fosse um ator a encenar suas falas e ações em um palco-cenário. Neste salutar estudo acerca das interações simbólicas, o conceito de pessoa é comparado a uma máscara que é utilizada para a encenação do sujeito. Dentro desta lógica a fachada pessoal é “o equipamento expressivo de tipo padronizado intencional ou inconsciente empregado pelo indivíduo durante sua representação" (GOFFMAN, 2002, p. 29). Com efeito, a representação necessita de daquela fachada para formar um cenário adequado no qual sua atuação possa ser coesa e coerente. Tal como um camaleão, o homem moderno líquido precisa cada vez mais dramatizar com leveza e dinamicidade suas múltiplas identidades no palco social que está inserido.

Ora, representar um papel social é pôr em prática uma conduta de certa forma institucionalizada. O indivíduo participa da sociedade incorporando padrões gerais de análise e compreensão do ambiente em que se movimenta, algo similar a uma bússola. Entretanto, a liquidez do mundo pós-moderno narrado por Bauman trouxe bastante complexidade para esse sistema de representação. Para Berger e Luckmann “o problema de reunir as várias representações em um todo 
coerente" (BERGER E LUCKMANN, 1976, p. 104) é fator central na lógica dos papéis sociais e das tipificações presentes na sociedade. Ou seja, o indivíduo sofre a influência dessas leituras tipificadoras e constrói sua identidade a partir dessa compreensão.

Por isso, pode-se entender a identidade como uma metamorfose, algo em constante transformação e interação com o meio. O espetáculo -inserido também na liquidez desta modernidade esmiuçada por Bauman - reconduz o teatro da existência social a uma peça cada vez mais complexa e multifacetada, na qual os atores devem representar seus papéis com mais destreza, sendo capazes também de trocar de personagem com grande rapidez.

Bauman assim explicita a problemática:

O futuro sempre foi incerto, mas seu caráter inconstante e volátil nunca pareceu tão inextricável como no líquido mundo moderno da força de trabalho "flexível", dos frágeis vínculos entre os seres humanos, dos humores fluidos, das ameaças flutuantes e do incontrolável cortejo de perigos camaleônicos" (BAUMAN, 2005, p 74).

Conforme exposto, o colapso do processo de identificação traçado pelo referido autor traz à tona um mecanismo ambivalente de atração-repulsa que acaba por ampliar sentimentos de angústia, ansiedade e desalento. $\mathrm{O}$ indivíduo camaleônico pós-moderno aduz esta mesma consciência paradoxal. Necessita camuflar-se diante de cenários sociais como artifício de sobrevivência: esta qualidade mutante é ao mesmo tempo sua maldição e sua salvação.

Pode-se, mediante a análise deste sistema dúbio por agora trabalhado, obter na obra surrealista "Metamorfose" de Franz Kakfa um potente instrumento de compreensão da angústia identitária do homem líquido moderno de Bauman. Na narrativa, o protagonista Gregor Samsa enfrenta o horror de acordar metamorfoseado em uma barata gigante e 
tenta encontrar meios que enfrentar esta nova e incongruente condição. Como explicar essa mudança? Tal como Gregor, o indivíduo vivencia o medo e o desconforto de encontrar-se transformado em um novo ser estranho e alheio a sua autoimagem percebida, vestindo assim uma carapaça que não entendia anteriormente como sendo sua. A alegoria kakfaniana, publicada em 1915, comunga em até certo ponto com o argumento aqui proposto, tal como o protagonista, os indivíduos no cenário atual líquidoque vivencia, assume novas vestes e novas identidades,sendo nem sempre estas foram escolhidas por eles mesmos e assim, tem que se adaptar as novas conjunturas e situações.

\section{Consumo, fluidez e ambivalência}

O fenômeno do consumo de massa é percebido por Bauman como um pilar do mundo líquido moderno na proporção em que amolda uma nova realidade imperativa para o indivíduo. Consumir parece ser a teia que liga as pessoas a importantes redes de sociabilidades como a moda, a cultura pop, as tecnologias da comunicação, as redes sociais... conectados à fluidez nos dias atuais, desejos e ambições passam a seduzir - e até certo ponto assediar - as pessoas aos ditames da obsolescência e a hipervelocidade transformadora da sociedade de consumo.

Desta feita, no processo histórico de passagem da society of producers para a society of consumers, a identidade transmuta-se também em um fenômeno de consumo. Bauman relata que:

Somos consumidores numa sociedade de consumo. A sociedade de consumo é a sociedade do mercado. Todos estamos dentro e no mercado, ao mesmo tempo clientes e mercadorias. Não admira que o uso/consumo da relações humanas, e assim, por procuração, também de nossas identidades (nós nos identificamos em referência a pessoas com as quais 
nos relacionamos), se emparelhe, e rapidamente, com o padrão de uso/consumo de carros, imitando o ciclo que se inicia na aquisição e termina no depósito de supérfluos! (BAUMAN, 2005, p. 98).

Para o autor, essa passagem deu nova roupagem ao capitalismo no mundo líquido moderno, na medida em que elevou o fenômeno do consumo como escopo precípuo da sociedade atual. Este fator é operacionalizado pelo que Bauman chamou de "cultura da oferta" (BAUMAN, 2009, p. 33): uma abastança sedutora que coage os indivíduos a fazer repetidas escolhas para a satisfação de novos desejos introjetados por essa cultura.

Com a identidade não poderia ser diferente, a possibilidade da escolha, mais do que um direito dos indivíduos, passa também a configurar-se como um dever:

\footnotetext{
A cultura também se transforma num armazém de produtos destinados ao consumo cada qual concorrendo com os outros para conquistar a atenção inconstante/errante dos potenciais consumidores, na esperança de atraí-la e conservá-la por pouco mais de um breve segundo (BAUMAN, 2009, p. 34).
}

Urge ressaltar que nesse cenário, os estímulos do mundo exterior ao individuo apresentam um forte potencial encantador que compele permanentemente as massas a comprar bens de consumo em novos templos de adoração: os shopping centers. Todo esse movimento aglutina-se com perfeição a conjuntura instável e mutante da sociedade líquida moderna de Bauman fragmentada e individualizada.

Outra contribuição deveras importante para o estudo da problemática provém dos escritos do sociólogo jamaicano Stuart Hall e seu trabalho: Identidade cultural na pós-modernidade. Nesta obra, o autor avalia quais as consequências da crise da identidade no mundo atual e para onde esta parece apontar no horizonte futuro. Segundo sua percepção: 
A questão da identidade está sendo extensamente discutida na teoria social. Em essência, o argumento é o seguinte: as velhas identidades, que por tanto tempo estabilizaram o mundo social, estão em declínio, fazendo surgir novas identidades e fragmentando o indivíduo moderno, até aqui visto como um sujeito unificado. A assim chamada "crise de identidade" é vista como parte de um processo mais amplo de mudança, que está deslocando as estruturas e processos centrais das sociedades modernas e abalando os quadros de referência que davam aos indivíduos uma ancoragem estável no mundo social (HALL, 2002, p. 7).

Na visão do sociólogoem questão, a identidade compõe-se de um arranjo de significados que localizam o sujeito no mundo dando-lhe uma confortável sensação de pertencimento. Todavia, o fenômeno da globalização tem deslocado continuamente as identidades culturais (aqui percebidas como nacionais) para um espaço desintegrador que não pode dar sinais de perpetuidade diante da ruptura da tradição.

Para Stuart Hall: “A globalização implica um movimento de distanciamento da ideia sociológica clássica da "sociedade" como um sistema bem delimitado" (HALL, 2002, p. 67-68). Esse sintoma tem fortes repercussões também na representação identitária que agora se torna mais ampla sob novas perspectivas. Por intermédio dos meios de comunicação que atravessam o mundo numa fração de segundo, um jovem da Índia pode identificar-se com símbolos da cultura inglesa ou norte-americana e apropriar-se destes para si, como se fossem seus. Stuart Hall chama o fim deste interregno entre cultura nacional e cultura global de "identidades partilhadas" (HALL, 2002, p.74).

Por óbvio que a globalização expande os limites da sociedade na noção de comunidade global onde o tempo e o espaço parecem, cada dia mais, aspectos superados. Entretanto, na visão baumiana, a liga que une as mais diversas culturas hoje é o consumo. Para ele aparenta não haver limites, nem fronteiras. Fruto disso é a terminal separação mútua entre 
poder e política (BAUMAN, 2011, p. 35) onde o Estado sai enfraquecido dessa ruptura. O poder desliza para novas mãos no capitalismo financeiro global das grandes corporações multinacionais onde a cadeia de produção de um bem de consumo pode facilmente abranger três países, cada um em um continente diverso.

A construção identitária do self também surfa neste mesmo mar instável de ondas grandes e violentas e perpassa por seu paradigma central: a ambivalência entre o desejo de pertencimento a um grupo e o anseio de conservar sua individualidade, não sendo desse modo engolida pelo mesmo. Bauman cita as duas forças que na sua leitura são provedoras dessa contenda: a segurança e a liberdade (BAUMAN, 2011, p. 24). Forças estas que estão em proporção inversa e por isso mesmo tendem a anular-se. Ou seja, na visão do autor, na medida em que uma cresce a outra cede espaço.

Assim, a identidade no mundo líquido moderno acompanha esse dilema e tenta reinventar-se. Aparenta no movimento atual ter adquirido mais liberdade e autonomia na busca encantadora do homem pela sua individualidade supostamente construída. Contudo, demonstra perder em segurança e estabilidade. Bauman julga que este cenário traz consigo a marca da frustração e da ansiedade avassaladora dos dias atuais.

\section{Conclusão}

A incompletude imperativa é carater fundamental da identidade na atual modernidade líquida. Bauman observa o complexo processo de construção do eu social como um fenômeno marcadopor umaprofunda ambivalência. Ao mesmo tempo em que este parece libertar o homem de suas amarras políticas, históricas e morais, parece largá-lo a própria sorte num cabedal de caminhos e escolhas infinitas. 
Assim, a identidade éafetada por esta fragmentação dos laços sociais que acaba por empurrar o sujeito para o isolamento, a desorientação e o desamparo. A regra é: você pode escolher o que quiser, desde que continue consumindo e se movimentando em alta velocidade. Talvez na próxima compra você encontre a verdadeira felicidade na paz da realização de um desejo que já lhe foi introjetado anteriormente.

Nessa sociedade cada vez mais privatizada e desregulamentada, o sujeito redefine constantemente sua identidademodulando sua bússola social para novos horizontes encantadores.Porém antes mesmo de chegar ao seu destino final, outro caminho lhe chama a atenção e tudo precisa ser reavaliado. A sensação de frustração e instabilidade é gritante.Bauman vê esse fato com profundamente desalentador e produtor de ansiedade nos dias hodiernos posto que redefinir seu propósito de vida é uma tarefa deveras fatigante para qualquer um que se encontre nessa encruzilhada.

Daí a alegoria do cameleão ser tão salutar para a melhor compreensão da relação indivíduo e sociedade líquida moderna. Se identidade pressupõe tornar algo único, com características singulares, deve-se observar que a realidade tem constrangido os sujeitos a comportarem-se como verdadeiros camaleões, promovendo mutações identitárias constantes na forma como estes se apresentam para o mundo exterior.

Nesse diapasão, essa tarefa de camuflagem como técnica de reacomodação do homem na sociedade é condicionante do que Bauman chamou de "política da vida"(BAUMAN, 2009, p. 33). Essa exigência de escolher caminhos cada vez mais fragmentários e enganadores dá causa para uma visceral angústia que é operacionalizada pelo consumo exacerbado e pela ansiedade latente.

Portanto, a liquidez presente nos dias cotidianos é fator precípuo para a correta análise dos fatos que permeiam a existência dos 
homens em sociedade. Bauman deixou vasta literatura que instiga novos estudos acerca dos mais variados temas, todos interligados pelo constante mal-estar que habita a existência humana hoje. A questão identitária é uma dessas problemáticas centrais e merece bastante atenção dos estudos sociológicos, pois afinal, responde a tão simples e ao mesmo tempo complexa indagação: quem sou eu?

\section{REFERÊNCIAS}

BAUMAN, Zygmunt. A cultura no mundo líquido moderno. Rio de Janeiro: Jorge Zahar Editora, 2011. 2009.

Capitalismo parasitário. Rio de Janeiro: Jorge Zahar Editora, Identidade: entrevista a Benedetto Vecchi. Rio de Janeiro: Jorge Zahar Editora, 2005.

. Modernidade líquida. Rio de Janeiro: Jorge Zahar Ed., 2001.

BERGER, P. L. \& LUCKMAN, T. A Construção Social da Realidade. Petrópolis: Vozes, 1976.

GOFFMAN, Erving. A representação do eu na vida cotidiana. 10. ed. Petrópolis: Vozes, 2002.

HALL, Stuart. A identidade cultural na pós-modernidade. $7^{\mathrm{a}}$ ed. Rio de Janeiro: DP\&A, 2002.

FRANZ, Kafka. A metamorfose. $14^{\circ}$ ed. Tradução de Modesto Carone, Companhia das Letras, São Paulo, 1997. 